\title{
SISTEM INFORMASI BURSA KERJA KHUSUS (BKK) BERBASIS WEB PADA SMK NEGERI 1 BANJARMASIN \\ Fitrah Yuridka ${ }^{1}$ )

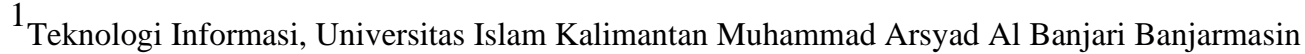 Email : vitrahyuridka@gmail.com
}

\begin{abstract}
ABSTRAK
Sekolah Menengah Kejuruan Negeri 1 Banjarmasin adalah salah satu Sekolah Menengah Kejuruan Negeri yang ada di kota Banjarmasin. Sekolah ini beralamat di Jalan Mulawarman No.45 Banjarmasin. Sekolah ini merupakan salah satu sekolah kejuruan favorit di kota Banjarmasin karena berhasil mencetak lulusan-lulusan yang berkualitas dan siap kerja berdasarkan pelajaran yang diberikan di sekolah ini maupun melalui pengalaman yang diberikan sekolah kepada siswa melalui program 'PRAKERIN' (Praktik Kerja Industri) atau sering disebut magang. Sekolah ini sudah bekerja sama dengan beberapa perusahaan baik negeri maupun swasta untuk menempatkan siswa-siswinya dalam praktik kerja industri.

Hingga saat ini SMK Negeri 1 Banjarmasin masih menggunakan semi manual dalam melakukan pengolahan data surat menyurat, dimana data yang ada masih dicatat dalam berkas serta membuat arsip surat menyurat masih menggunakan MS.Word dan MS. Excel, proses pencarian data pun masih terbilang sulit karena informasi tidak didokumentasikan dengan baik.

Dengan adanya Sistem Informasi Bursa Kerja Khusus SMK Negeri 1 Banjarmasin pembuatan laporan surat masuk dan surat keluar bisa dilakukan dengan cepat dan tepat. Sitem pengolahan surat masuk dan surat keluar terkomputerisasi adalah sebagai sarana informasi untuk staf tata usaha agar dapat mempermudah dalam pengelolaan surat. Metode yang digunakan untuk pengembangan aplikasi ini adalah metode Waterfall dengan tujuan untuk meminimalisir terjadinya kesalahan.
\end{abstract}

Kata Kunci : Aplikasi, BKK, Surat, SMKN 1 Banjarmasin, Sublime text3, Web. 


\section{PENDAHULUAN}

BKK adalah sebuah lembaga yang dibentuk di Sekolah Menengah Kejuruan Negeri dan Swasta, sebagai unit pelaksana yang memberikan pelayanan dan informasi lowongan kerja, pelaksana pemasaran, penyaluran dan penempatan tenaga kerja,saat ini SMK Negeri 1 Banjarmasin masih menggunakan semi manual dalam melakukan pengolahan data bursa kerja khusus, dimana data yang ada masih dicatat dalam berkas serta membuat arsip bursa kerja khusus masih menggunakan MS Word dan MS. Excel. Penggunaan komputer untuk membantu pengolahan data belum dapat dilakukan secara optimal, Hal ini dikarenakan adanya beberapa kelemahan, yakni pengolahan data yang kurang efektif dan efisien, keterlambatan dalam proses pencarian data, bahkan data yang ada mempunyai risiko rusak ataupun hilang. Dilihat dari sarana tersebut, diperlukan suatu sarana penunjang yang mampu meningkatkan efektifitas dan efisiensi pengolahan data bursa kerja khusus secara maksimal.

\section{METODE PENELITIAN}

\subsection{MetodePengumpulan Data}

Data primer merupakan data yang langsung dapat dan disajikan sebagai sumber dari penelitian dan pengamatan secara langsung pada objek atau perusahaan tempat melakukan penelitian, dimana dilakukan dengan cara penelitian lapangan melalui observasi dan wawancara dengan pihak yang berkaitan langsung dengan penelitian yang dilakukan, sedangkan data sekunder adalah dengan cara studi literatur dan wawancara. analisa data dan hasil.

\subsection{Tahap-Tahap Pembuatan Sistem}

\section{Analisis Sistem}

Tahap yang dilakukan untuk pengembangan perangkat lunak ini adalah menggunakan metode waterfall, dimana tahapan-tahapannya adalah sebagai berikut :

a. Requirement Analysis / Analisa Kebutuhan :Menganalisa kebutuhan kebutuhan yang diperlukan untuk mengembangkan aplikasi. Fase ini dapat diperoleh melalui wawancara, diskusi, survey, riset maupun dari kritik dan saran sering disebut studi literatur.

b. System Design / DesainSistem :Tahap yang dilakukan sebelum kita menerapkan syntax atau kode-kode program.

c. Implementation / Implementasi : Tahap perancangan kode atau syntax

d. Integration \& Testing / Integrasi dan pengujian :melakukan koding ulang terhadap kesalahan sampai error dapat ditangani.

e. Operation \& Maintenance / Penggunaan dan Pemeliharaan :seiring berjalannya waktu pengguna aplikasi pasti menemukan bug / error kecil yang tidak ditemukan pada saat pengujian, dan pada fase ini lah melakukan perbaikan - perbaikan terhadap aplikasi. Pada tahap ini tidak selalu harus terjadi error untuk melakukan fase ini, menemukan sesuatu yang tidak sesuai atau bisa diubah menjadi lebih baik, maka tahap ini bisa dilakukan juga.

\section{Perancangan Sistem}

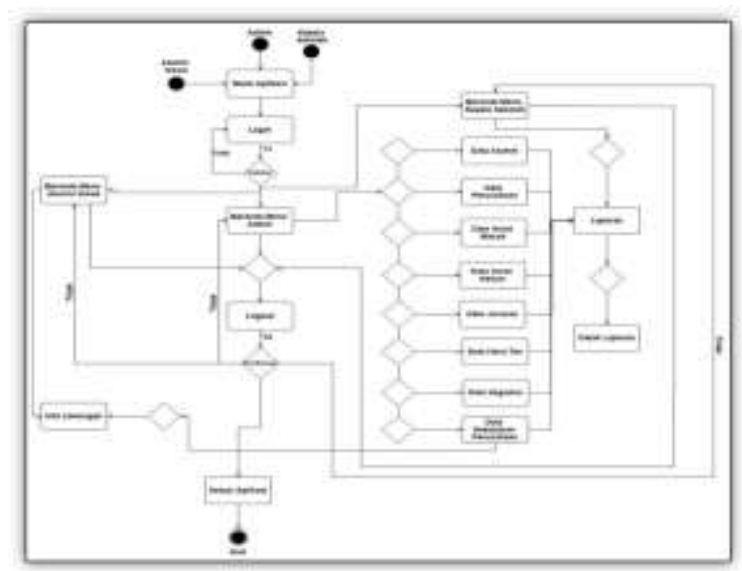

Gambar 1. Activity Diagram 


\section{HASIL DAN PEMBAHASAN}

3.1 Tampilan Sistem

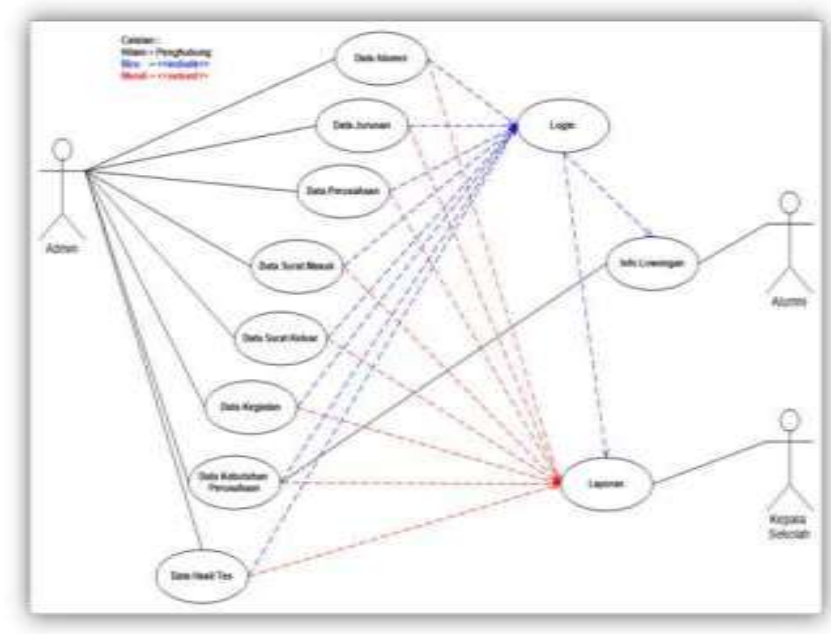

Gambar 2. UseCase Diagram

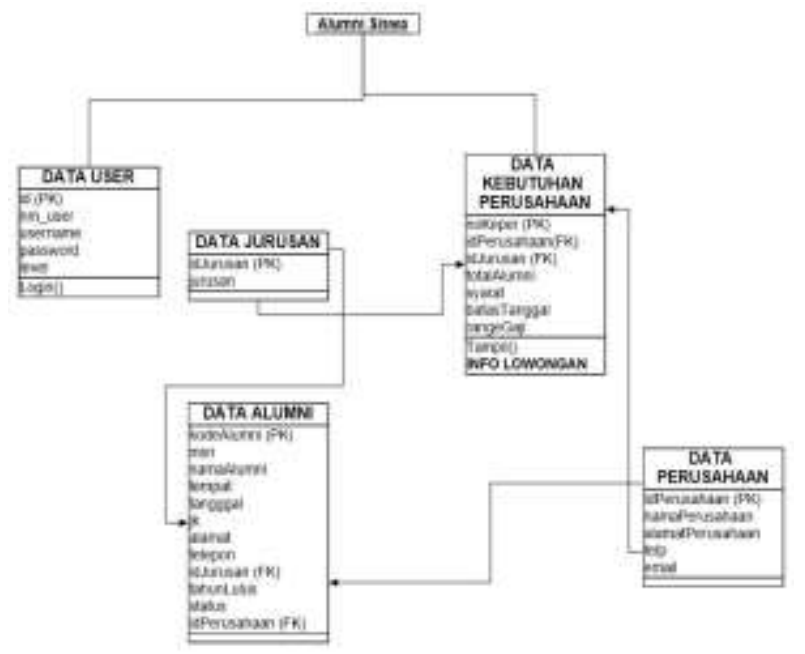

Gambar 3. Class Diagram Alumni Siswa

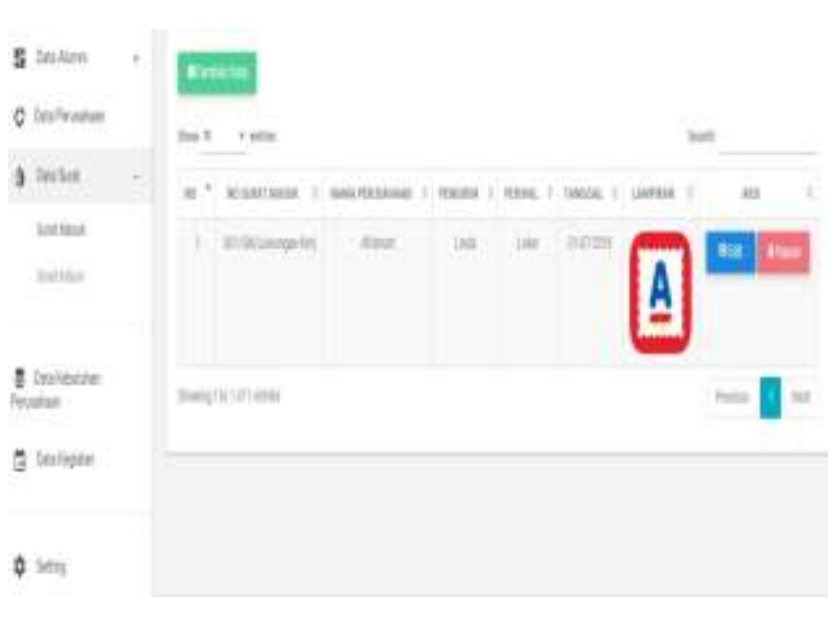

Gambar 4. Form Input Data Surat Masuk

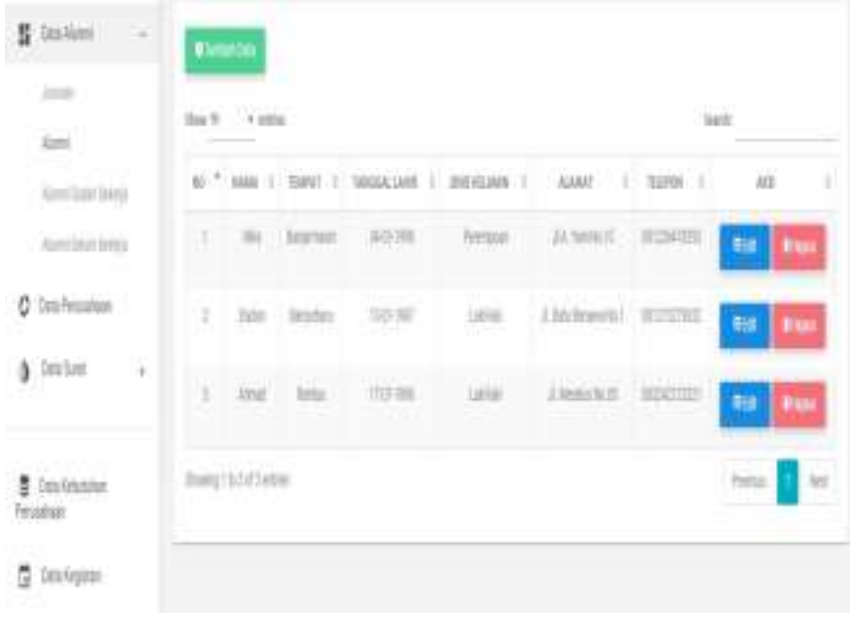

Gambar 5. Form Data Input Alumni

LAPORINDITASIRATMASIK

\begin{tabular}{|c|c|c|c|c|c|}
\hline No & No Sarz: Yhatk & Yam Peraiatun & Peagirin & Peritat & Tangel \\
\hline$T$ & 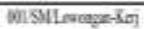 & Afinst & Linds & Ladar & 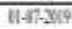 \\
\hline
\end{tabular}

Jenhat 15 arz Kadk 
4. Kesimpulan

Dapat disimpulkan bahwa pembuatan aplikasi ini dapat mempermudah pengelolaan data dan meningkatkan efisiensi kerja bagian admin BKK SMK Negeri 1 Banjarmasin yaitu dengan cara mengembangkan sistem yang bersifat manual menjadi komputerisasi dengan menggunakan Web.

\section{Referensi}

(1) Irmansyah, Faried, 24 April 2007, Pengantar Database.

(2) Kendal.2002. Analisis dan Perancangan Sistem.Jakarta.Prenhallindo.

(3) Kristanto, Harianto.1994, Konsep dan Perancangan Database. Yogyakarta : Andi Yogyakarta

(4) Modeling Classroom: An Introduction to Object-Oriented . Heidelberg:dpunkt.verlag.

(5) Martina Seidl, M. S. (2014). UML @lassroom: An Introduction to ObjectOriented 